\title{
A global survey of aerosol-liquid water cloud overlap based on four years of CALIPSO-CALIOP data
}

\author{
A. Devasthale ${ }^{1}$ and M. A. Thomas ${ }^{2}$ \\ ${ }^{1}$ Remote Sensing Division, Swedish Meteorological and Hydrological Institute, Norrköping, Sweden \\ ${ }^{2}$ Air Quality Division, Swedish Meteorological and Hydrological Institute, Norrköping, Sweden
}

Received: 13 August 2010 - Published in Atmos. Chem. Phys. Discuss.: 27 September 2010

Revised: 17 January 2011 - Accepted: 4 February 2011 - Published: 10 February 2011

\begin{abstract}
Simulating the radiative impacts of aerosols located above liquid water clouds presents a significant challenge. In particular, absorbing aerosols, such as smoke, may have significant impact in such situations and even change the sign of net radiative forcing. It is not possible to reliably obtain information on such overlap events from existing passive satellite sensors. However, the CALIOP instrument onboard NASA's CALIPSO satellite allows us to examine these events with unprecedented accuracy. Using four years of collocated CALIPSO $5 \mathrm{~km}$ Aerosol and Cloud Layer Version 3 Products (June 2006-May 2010), we quantify, for the first time, the characteristics of overlapping aerosol and water cloud layers globally. We investigate seasonal variability in these characteristics over six latitude bands to understand the hemispheric differences when all aerosol types are included in the analysis (the AAO case). We also investigate frequency of smoke aerosol-cloud overlap (the SAO case). Globally, the frequency is highest during the JJA months in the AAO case, while for the SAO case, it is highest in the SON months. The seasonal mean overlap frequency can regionally exceed $20 \%$ in the AAO case and $10 \%$ in the SAO case. In about $5-10 \%$ cases the vertical distance between aerosol and cloud layers is less than $100 \mathrm{~m}$, while about in $45-60 \%$ cases it less than a kilometer in the annual means for different latitudinal bands. In about $70-80 \%$ cases, aerosol layers are less than a kilometer thick, while in about $18-22 \%$ cases they are 1-2 km thick. The frequency of aerosol layers $2-3 \mathrm{~km}$ thick is about $4-5 \%$ in the tropical belts during overlap events. Over the regions where high aerosol loadings are present, the overlap frequency can be up to $50 \%$ higher when quality criteria on aerosol/cloud feature detection are relaxed. Over the polar regions, more than $50 \%$ of the overlapping aerosol layers have optical thickness less than 0.02 , but the
\end{abstract}

Correspondence to: A. Devasthale (abhay.devasthale@smhi.se) contribution from the relatively optically thicker aerosol layers increases towards the equatorial regions in both hemispheres. The results suggest that the frequency of occurrence of overlap events is far from being negligible globally.

\section{Introduction}

The last few years has seen intense research into both direct and indirect radiative effects of aerosols (refer comprehensive reviews by Carslaw et al., 2010; Lohmann and Feichter, 2005; Quaas et al., 2009a; and references therein). Aerosols can potentially have multiple effects on clouds. The most recent report by the Intergovernmental Panel on Climate Change (IPCC) now recognizes more indirect aerosol effects compared to its previous assessments (IPCC, 2007). However, the uncertainty estimates of these aerosol-cloud interactions reflect our limited knowledge on them, although there have been considerable improvements from both observational and modeling perspectives (Stevens and Feingold, 2009). Global aerosol and cloud systems show strong spatio-temporal heterogeneity and the in-situ measurements of their key properties remain sparse. Among many other aspects, this poor characterization of aerosol and cloud properties partly contributes to the uncertainties in estimating direct and indirect effects, their relative importance, and their sensitivity to meteorology and large scale dynamics on a global scale. This field of research remains far from being matured, although satellite observations have partially helped to close the knowledge gap. One good example is ongoing research on physical interpretation of the positive relationship between satellite derived aerosol optical depth and cloud cover (Quaas et al., 2009b; and references therein). These uncertainties challenge us so much so that we need to revisit and understand the basic definitions of aerosol and cloud (Koren et al., 2007, 2008). 
In the context of simulating aerosol radiative effects, it can be argued that the most complex situations are present in the atmosphere when aerosols overlap very bright water cloud tops (Brioude et al., 2009; Chand et al., 2008, 2009; Peters et al., 2009; Waquet et al., 2009). There are many reasons as to why the quantification of aerosol-cloud overlap characteristics is necessary. Few of them are listed below.

1. Whether aerosols exert a net positive or negative direct radiative forcing is, apart from optical properties, composition and size distribution, shown to be dependent on underlying cloud cover (Chand et al., 2009). As the amount of overlap increases, the system is likely to exert a net warming effect in case of absorbing aerosols such as smoke.

2. Resolving uncertainties in aerosol cloud interactions (e.g. AOD-cloud cover relationship, cloud-lifetime effect, semi-direct effect) requires knowledge on how closely they are placed horizontally and vertically. This has a direct influence on various processes, for example, cloud-top entrainment, cloud processing of aerosols, humidification and swelling of aerosols in the vicinity of clouds etc.

3. It is necessary to investigate characteristics of overlapping events to assess biases in cloud property retrievals as they are observed to be sensitive to the overlying aerosol layers (Wilcox et al., 2009). This is especially required for datasets from the heritage sensors like, Along Track Scanning Radiometer (ATSR), Advanced Very High Resolution Radiometer (AVHRR) and Moderate Resolution Imaging Spectroradiometer (MODIS), where potential climate monitoring capabilities demand high accuracy retrievals.

However, detecting aerosol-cloud overlap from the existing passive satellite sensors is extremely difficult and the quantification of overlap characteristics is not possible. One of the revolutionary advantages of Cloud-Aerosol Lidar with Orthogonal Polarization (CALIOP) sensor onboard NASA's Cloud-Aerosol Lidar and Infrared Pathfinder Satellite Observations (CALIPSO) satellite (Winker et al., 2009) is that it enables us to quantify overlapping cases and their characteristics. Although there are very few studies that investigate overlapping cases (e.g. Brioude et al., 2009; Chand et al., 2008, 2009; Peters et al., 2009; Waquet et al., 2009), a global assessment is still lacking.

In the present study, answers to the following three questions are sought.

1. How frequently distinct aerosol layers occur over low level water clouds seasonally and globally? Such frequency is expressed in the seasonal spatial maps.

2. How closely aerosol and water cloud layers are placed vertically during overlapping events? This is shown in the joint histograms of aerosol layer base height and cloud layer top height for six latitudinal bands.

3. How geometrically thick aerosol and thin cloud layers are in such overlapping cases? This is expressed in the joint histograms of aerosol and cloud geometrical thicknesses.

The next section provides a brief description of data used and its processing methodology followed by discussion of results. The last section concludes the paper.

\section{CALIPSO-CALIOP data processing}

We use the standard CALIPSO $5 \mathrm{~km}$ Aerosol and Cloud Layer Version 3 products (June 2006-May 2010) for analysis. These products, their theoretical basis algorithms and validations are described in the works by $\mathrm{Hu}$ et al., 2009; Liu et al., 2009; Omar et al., 2009; Vaughan et al, 2009; Winker et al., 2009; and Young and Vaughan, 2009. For the present study, it is important that the cloud-aerosol discrimination is achieved as accurately and realistically as possible. We use quality flags provided in these datasets and use collocated observations only when both of these features are detected with the highest confidence. The CALIPSO products are not entirely free from misclassifications, but nevertheless, they provide first such possibility to investigate aerosolcloud overlap. For aerosols, most of the misclassifications are so far reported for cases when there are heavy outbreaks of dust over the desert areas. But as we will show later, overlap events are uncommon over these areas. As for the clouds, very thin clouds can occasionally be misclassified as aerosols. But such cases are also uncommon in the lower troposphere.

We analysed data separately for DJF (December, January and February), MAM (March, April and May), JJA (June, July and August), and SON (September, October and November) months to investigate seasonal variability in overlap characteristics. We further subdivide the globe into six latitude bands, i.e. $0-30^{\circ} \mathrm{N}, 30^{\circ} \mathrm{N}-60^{\circ} \mathrm{N}, 60^{\circ} \mathrm{N}-82^{\circ} \mathrm{N}, 0$ $30^{\circ} \mathrm{S}, 30^{\circ} \mathrm{S}-60^{\circ} \mathrm{S}$, and $60^{\circ} \mathrm{S}-82^{\circ} \mathrm{S}$. It is to be noted that observations polewards of $82^{\circ}$ are not available from CALIPSO due to its narrow swath and orbital configuration. The spatial sampling/coverage of the CALIOP is not as good as imagers, but we argue that the observations compiled over four seasons should be sufficient to draw robust conclusions.

For each collocated profile from the layered products, we first search for an aerosol feature. If it is present, we examine its quality and proceed if it was detected with the highest confidence. We then check if there is an underlying water cloud layer present in the same profile. If so, we examine its quality and proceed if it was also detected with the highest confidence. We first search for aerosol layer and then an underlying cloud layer for computational efficiency reason as the number of cloud contaminated profiles is likely 

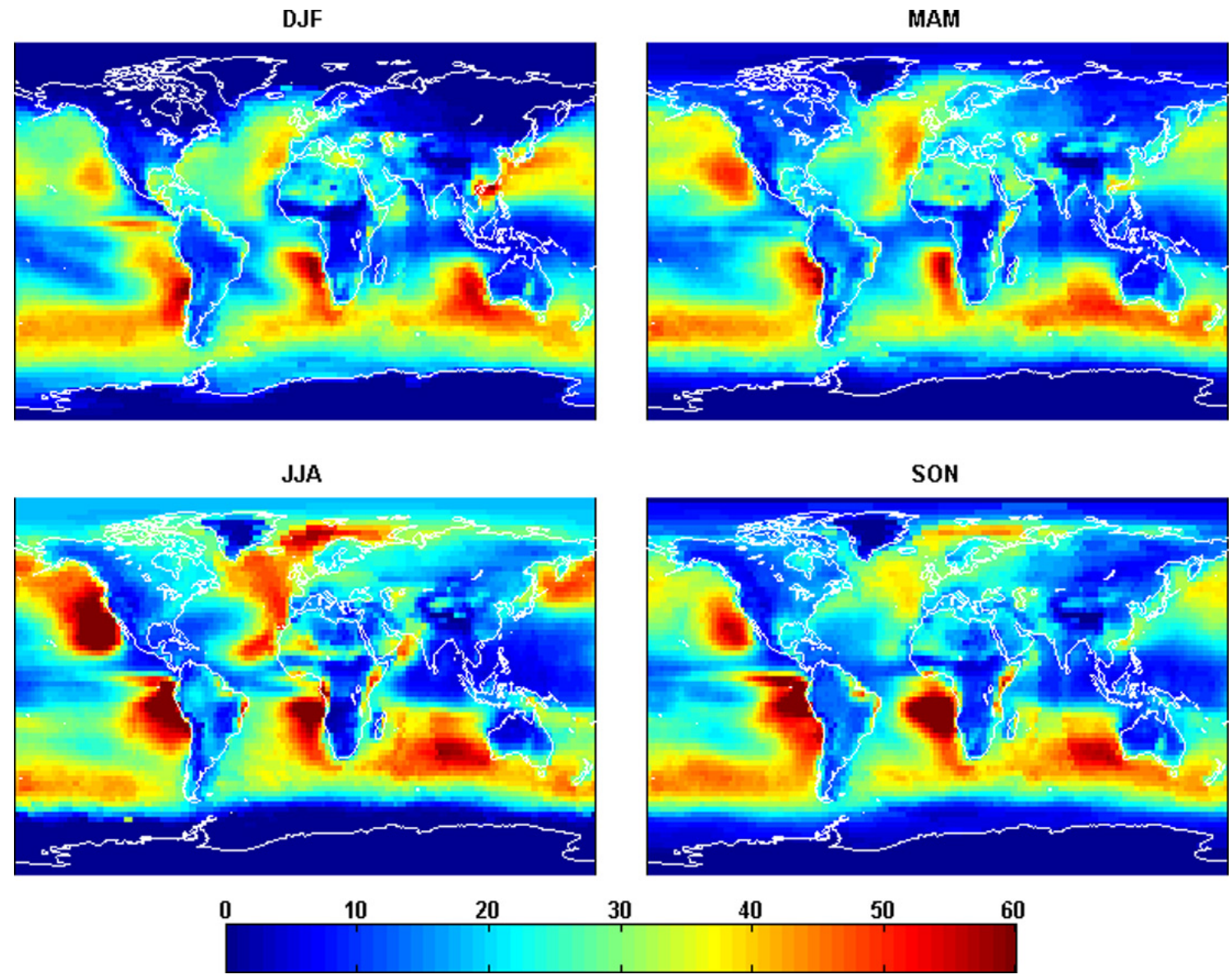

Fig. 1. A global climatological distribution (1983-2008) of daytime low level liquid water clouds derived from ISCCP D2 product for the DJF, MAM, JJA, and SON months. These data were obtained from the ISCCP website: http://isccp.giss.nasa.gov/products/browsed2.html.

to be very high. We calculate the fraction of these cases for each $1^{\circ} \times 1^{\circ}$ grid box by dividing the number of these high confidence overlapping cases by the total number of observations over this grid box (averaged over four seasons). The use of only high quality observations gives a lower estimate of overlap frequency. We further compute joint histograms of aerosol base height and cloud top height. The advantage of presenting these histograms is that, apart from obtaining information on two important parameters (i.e. cloud top and aerosol base altitudes), the vertical separation of the layers is also apparent. The closer the distribution is centered along the one-to-one line of the joint histogram, the smaller is the vertical separation of the aerosol and cloud layers. We investigate joint histograms of geometrical thicknesses of aerosols and cloud layers as they also play a substantial role in radiative transfer.

One of the many distinguishing features of CALIOP observations is their ability to classify aerosols into various categories. The standard $5 \mathrm{~km}$ Aerosol Layer data product provides classification of aerosols into six types, namely, clean marine, dust, polluted continental, clean continental, polluted dust, and smoke by making use of layer integrated at- tenuated backscatter and volume depolarization ratio (along with ancillary information on the surface type and layer height) and following a sound physical basis (Omar et al., 2009). By making use of such categorization, we compute overlap frequency also for smoke layers separately.

\section{Results on overlap statistics}

First, it is helpful to examine the climatological distribution of low level liquid water clouds and aerosols globally, in order to get an overview of regions where overlapping situations are most likely to occur. Since the large scale circulation has a first-order impact on the transport of aerosols over the oceans, it is necessary to discuss major wind patterns in this context. Figure 1 shows the climatological distribution of daytime low level liquid clouds and their seasonality based on the International Satellite Cloud Climatology Project (ISCCP) D2 data (1983-2008). It can be seen that oceanic areas where upwelling of cold water takes place along the western coasts of the continents show predominance of these clouds. For example, the parts of western coasts of the North and 


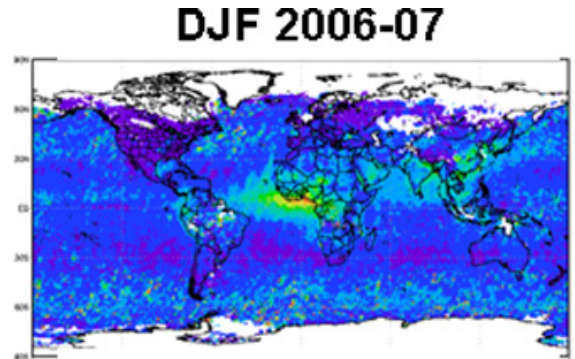

MAM 2007

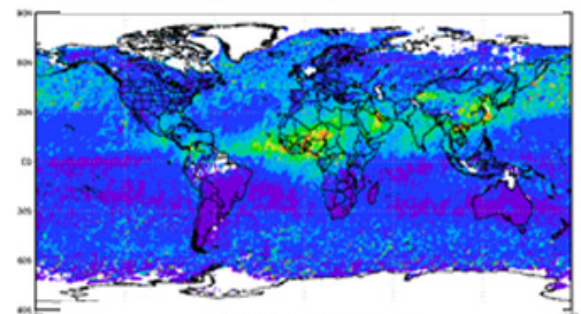

JJA 2006

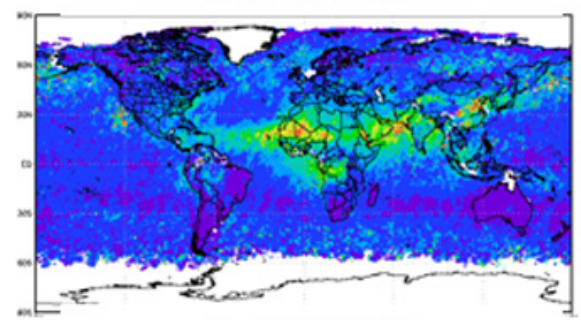

SON 2006

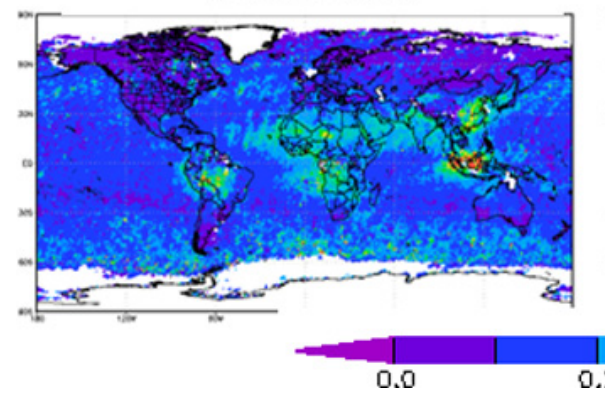

DJF 2007-08

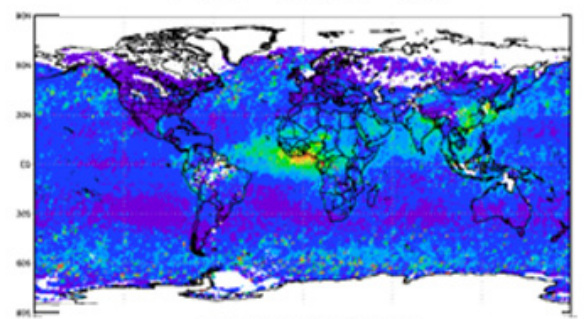

MAM 2008

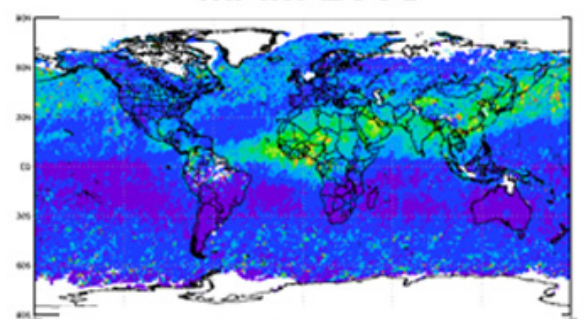

JJA 2007

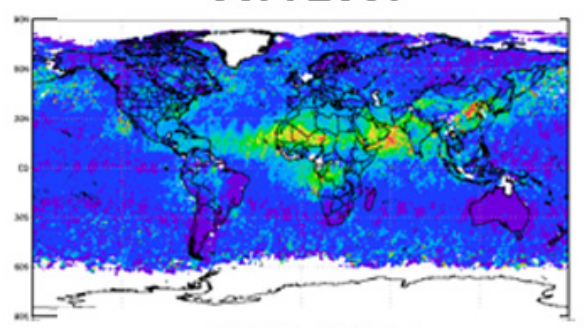

SON 2007

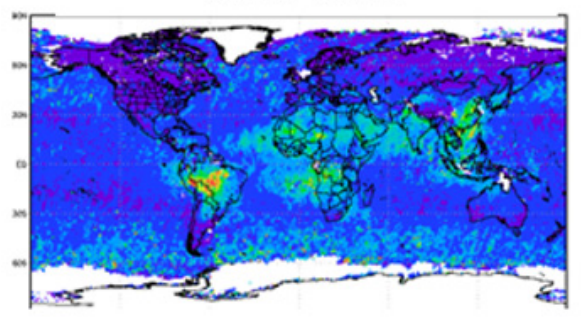

DJF 2008-09

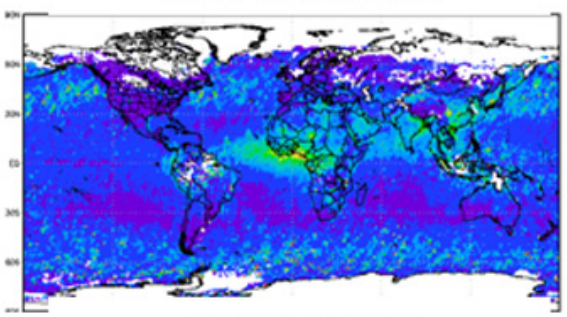

MAM 2009

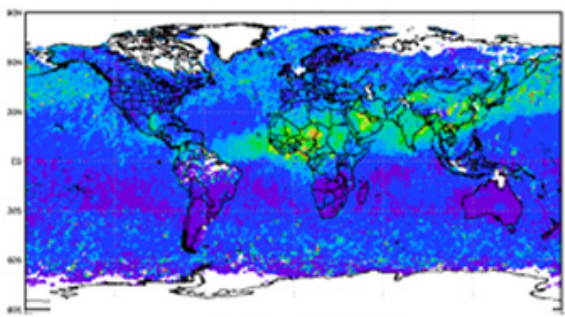

JJA 2008

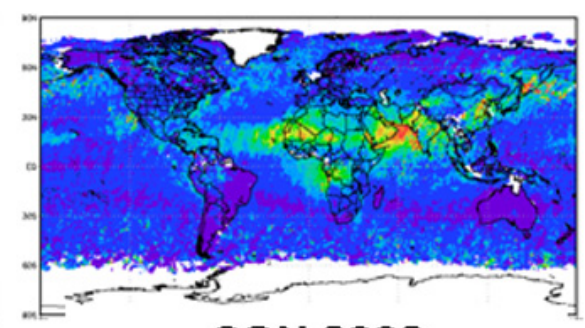

SON 2008

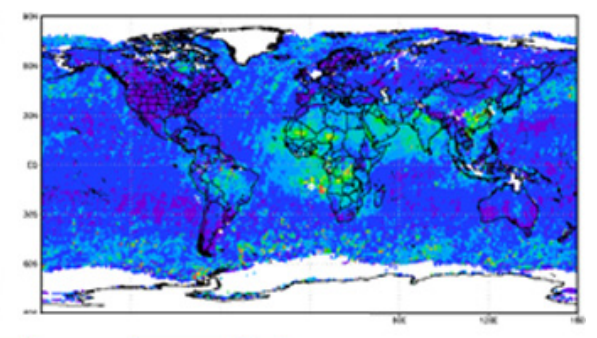

0.8

1.0

Fig. 2. Mean seasonal aerosol optical depths derived from the MISR sensor.

South American continents as well as southwestern coast of Africa show very high frequency of these clouds. Another region that stands out is the belt of low level cloudiness between latitudes $30^{\circ} \mathrm{S}-60^{\circ} \mathrm{S}$ in the Southern Ocean. Globally, the fraction of low level clouds is highest during the JJA months. A global view of aerosols (Fig. 2 and Remer et al., 2008) shows that there are many regions where aerosol-cloud overlaps are likely to occur, as both natural and anthropogenic aerosols are transported over oceanic areas where low level liquid clouds are common. For example, easterly and southeasterly winds (Supplement Figs. S1 and S2) transport biomass burning aerosols from southern Africa over to the South-East Atlantic Ocean, while westerly winds carry biomass burning and other aerosols over northern $\mathrm{Pa}$ cific Ocean from Siberia and the northeast Asian regions.
The Supplement Fig. S3 shows the typical global spatial distribution of burning events and their seasonality in terms of 10-day composite fire maps derived from the MODIS sensor for year 2008 to further facilitate interpretation of the results below.

The spatial patterns of overlap frequency and their seasonal variations are shown in Figs. 3 and 4. All aerosol types are considered for the results shown in Fig. 3 (hereafter denoted as the all-aerosol-overlap, AAO, case), while the results for only smoke aerosols are shown in Fig. 4 (the smoke-aerosol-overlap, SAO, cases). A distinct seasonality in overlap frequency is evident in both cases. The frequency is highest during the JJA months in the AAO case, while in the SAO case, it is highest in the SON months. 

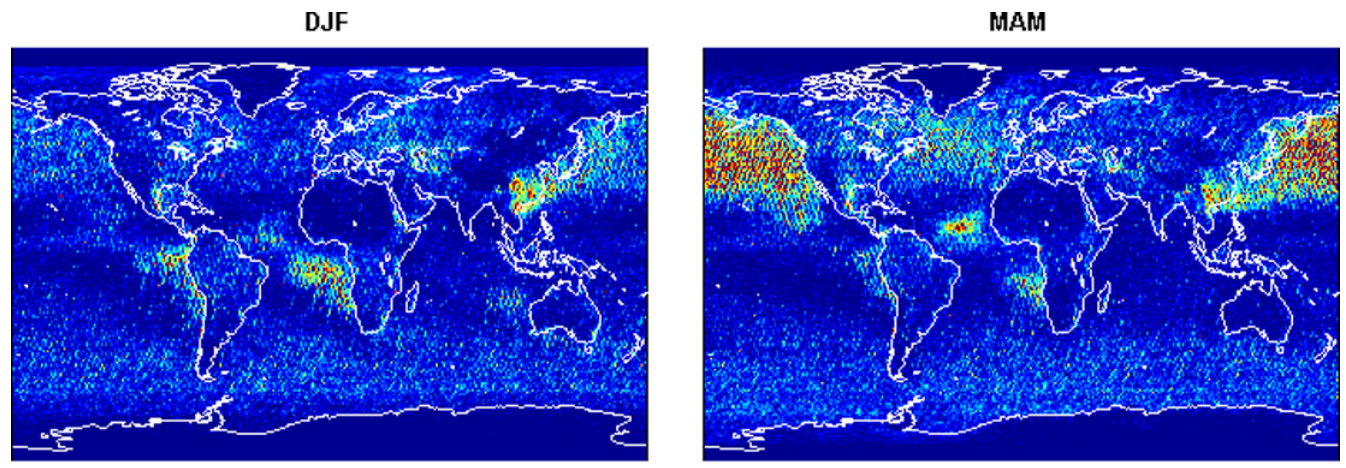

JJA
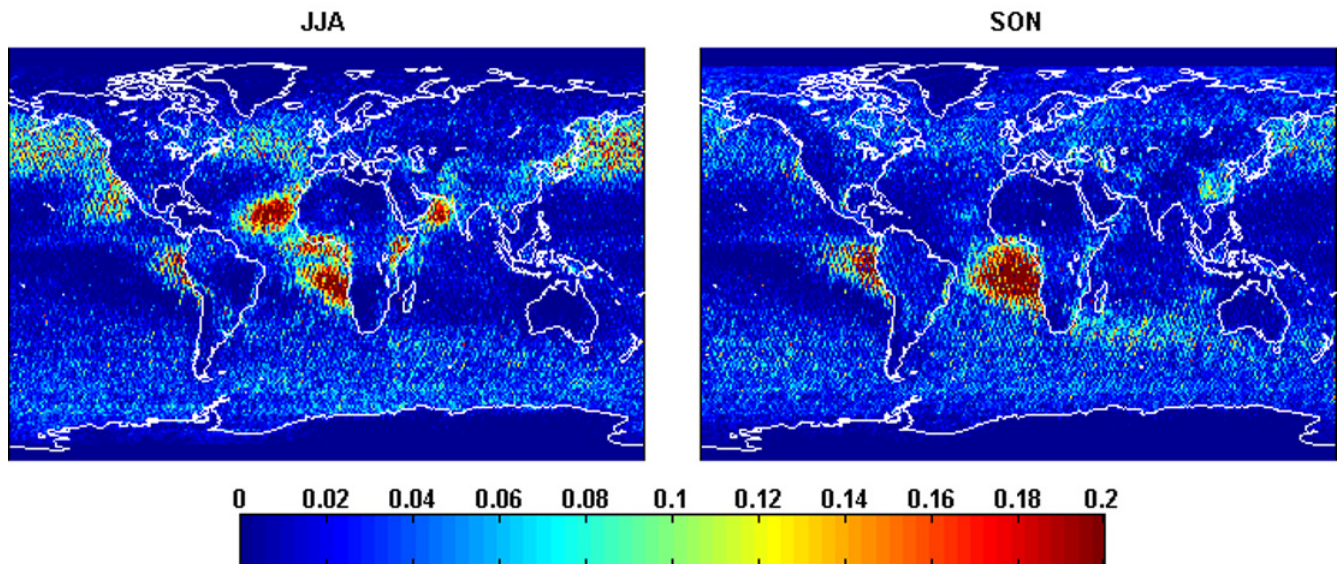

Fig. 3. The spatial and seasonal aerosol-water cloud overlap frequency when all aerosol types are considered for the analysis.

DJF

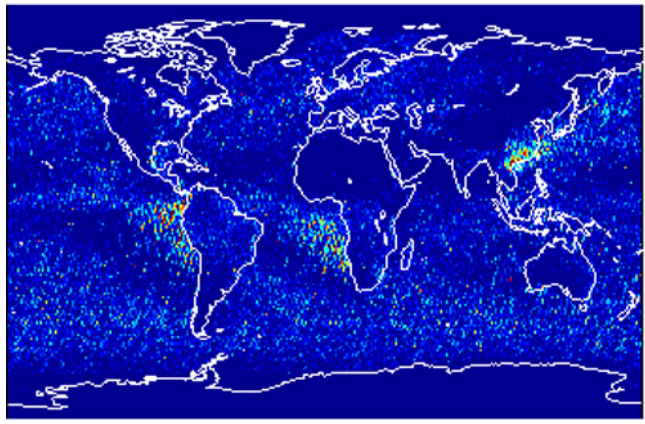

JJA
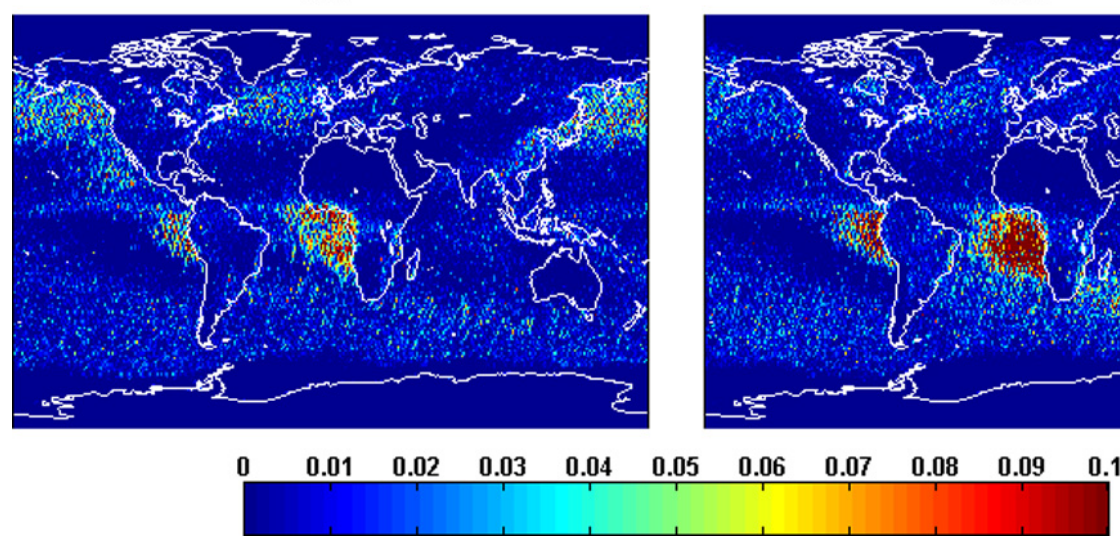

MAM

SON
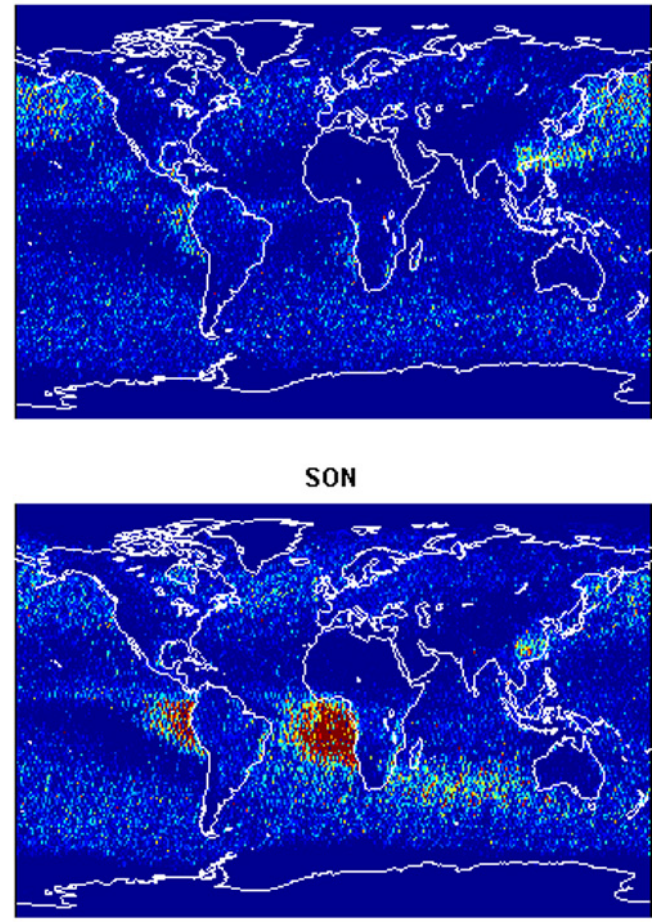

\section{(1)}

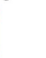

Fig. 4. Same is in Fig. 3, but for cases when only smoke layers are included in the analysis. 
In the DJF months, the maximum frequency is observed off the western coast of central Africa with values occasionally exceeding $15 \%$ for the AAO case. Based on the spatial distributions of low clouds and aerosols together with major circulation patterns, it can be deduced that easterly and northeasterly winds over arid as well as intense biomass burning regions of tropical savannas in sub-Saharan Africa transport dust and smoke aerosols south of the equator. The Multiangle Imaging Spectroradiometer (MISR) aerosol optical depth shows maximum values off the southern coast of Liberia, Ivory Coast, Ghana and Nigeria in the DJF months (Fig. 2). Aerosols from the regions of southwestern Africa are also transported above these clouds. Another region that shows high overlap frequency is China.

The transport of biomass burning and dust aerosols from the Eurasia region intensifies in the MAM months. The westerly winds advect these aerosols over northern Pacific Ocean off the eastern coasts of China, Russia and Japan, where low level clouds are also present in large amounts, resulting in high overlap frequency over this region $(>15 \%)$. The overlap frequency off western coast of sub-Saharan Africa is high in the AAO case, which may be due to the transport of pure and polluted dust as it is not seen in the SAO case. During the JJA months, oceanic areas along the eastern and western coasts of the African continent show high overlap frequency with mean values exceeding $20 \%$. Strong monsoonal winds (the Somali jet) lift and transport large quantities of dust aerosols from the east African and the Arabian Gulf regions over northern Indian Ocean and Arabian Sea (Satheesh et al., 2006), where shallow as well as deep convection is observed during the monsoon months. The observed overlap due to smoke aerosols is mostly off the western coast of southern Africa, where biomass burning is intensified during this season. The MISR AOD composites also show high values over southeast Atlantic Ocean and southern Africa. The overlap frequency is also very high off the western coasts of South America (Columbia, Ecuador, and Peru), and North America (California, USA, and western Mexican coast). During the SON months, aerosol transport from biomass burning regions of southern and central Africa as well as South America dominates the global distribution of overlap frequency (Andreae et al., 2001; Freitas et al., 2005).

Since we used the aerosol and cloud layers detected with the highest confidence for analysis (and thus providing the lowermost estimates of overlap frequency), we further investigated the sensitivity of our estimates to the aerosol and cloud feature detection quality flags. We reprocessed the entire four year data sets when (a) the quality flag for the aerosol feature is switched off (denoted by woAqual), (b) the quality flag for the cloud feature is switched off (woCqual), and (c) the quality flags for both aerosol and cloud features are switched off (woACqual). We then computed the zonal mean percentage differences in overlap frequency in the above three cases with respect to the case when the strictest quality criteria were used. The results of this sen- sitivity study are presented in Fig. 5 for the AAO case. In the tropics $\left(30^{\circ} \mathrm{S}-30^{\circ} \mathrm{N}\right)$, the estimates of overlap frequency are constrained by the quality of both aerosol and cloud features, however towards the higher latitudes, these estimates are constrained mainly by the aerosol feature quality flags. The seasonal changes in the zonal structure of the percentage differences for the woAqual case (in Fig. 5) also reflect the seasonal and zonal shifts in peak overlap frequencies in the tropics and the mid-latitudes (in Fig. 3). For example, in the SON months, the estimates of overlap frequencies are roughly $15-20 \%$ higher over the $0-50^{\circ} \mathrm{S}$ latitude band for the woAqual case, while in the MAM months, the estimates are higher over the $0-50^{\circ} \mathrm{N}$ latitude band. In general, the sensitivity of overlap frequency to the quality flags varies as a function of latitude and season. When all aerosol and cloud layers are considered for the analysis irrespective of their detection quality (the woACqual case), the percentage increase in overlap frequency can range anywhere between 10-50\% over the regions where aerosols are abundant. However for the following analyses, we prefer to use the strictest quality criteria so as to derive the least uncertain statistics. But for analyzing few days of data in the individual case studies, these quality criteria can be relaxed. Such broad range of sensitivity suggests that there is still some room for improvements in the feature detection algorithm.

As an aerosol optical depth is one of the key properties required to ascertain radiative impact of the overlying layers, we examined the zonal seasonal distribution of optical depths of the overlying aerosol layers as shown in Fig. 6 for the AAO case. Each bin in Fig. 6 is 0.02 optical depth units by one degree latitude. Each optical depth bin along y-axis is normalized by the total number of observations at a particular latitude bin, thus providing the fraction of observations represented by each optical depth bin at that particular one degree latitude. Over the polar regions, more than $50 \%$ of the overlapping aerosol layers have optical thickness less than 0.02 , but the contribution from the relatively optically thicker aerosol layers increases towards the equatorial regions in both hemispheres. In the tropics and the midlatitudes, roughly 30-50\% aerosol layers have optical thickness in the range of $0.02-0.04$. About $10-20 \%$ of aerosol layers have optical depths greater than 0.1 over these regions. There is also seasonality in the distribution of aerosol optical depths during overlapping events. In the summer half-year (i.e. from June till November), the frequency of occurrence of the optically thick aerosol layers (with optical depth $>0.1$ ) is at least twice to that of the winter-half year.

In addition to the aerosol optical depth, the vertical separation of aerosol and cloud layers and their geometrical thickness have an impact on radiative transfer by influencing multiple reflection and absorption processes locally. The altitudes at which these interactions occur play an important role in shaping radiative heating profiles during overlap events. Therefore, in order to gain information on the vertical distribution, observations of cloud layer top and aerosol 

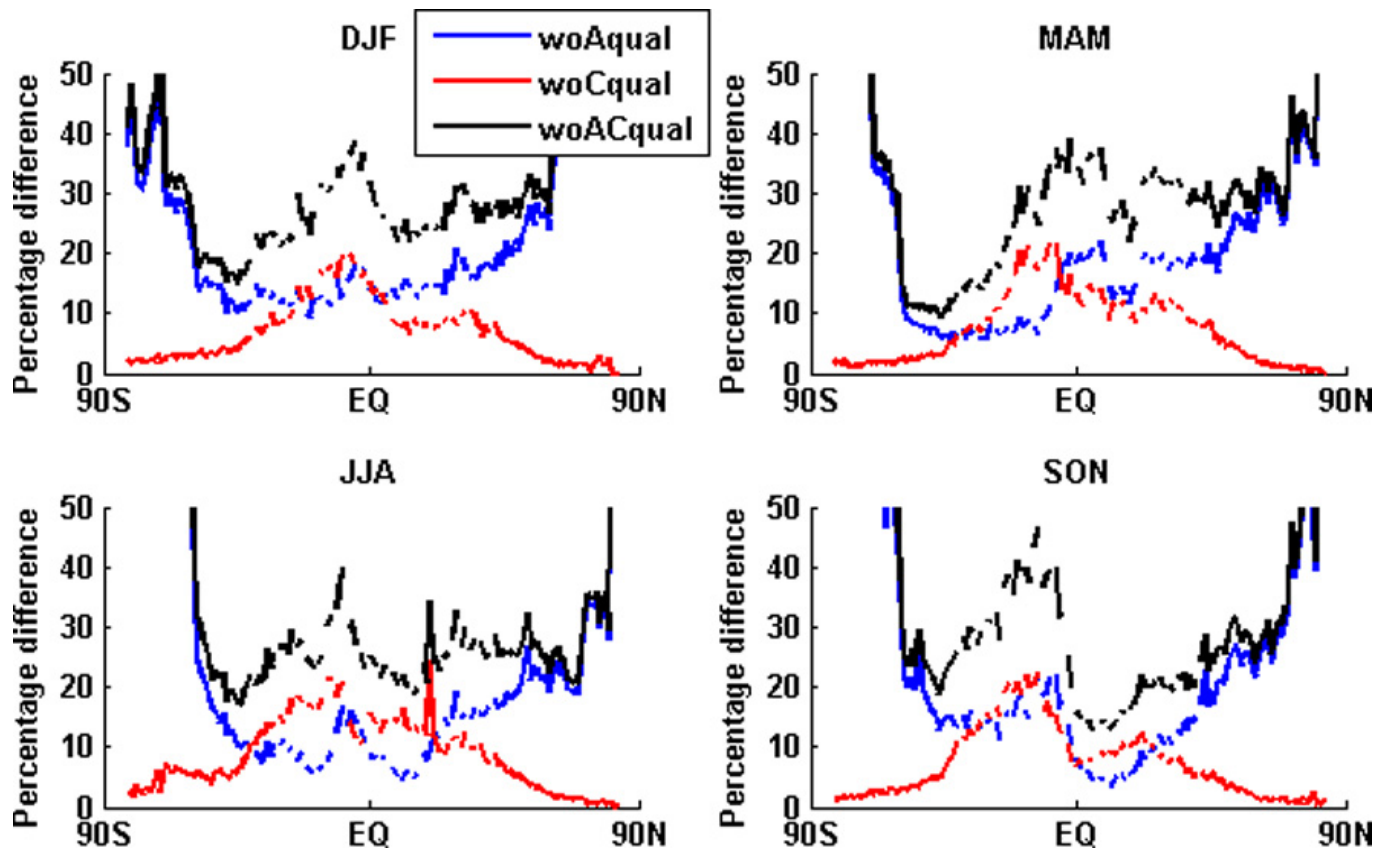

Fig. 5. The zonal mean percentage difference in overlap frequency when (a) the quality flag for the aerosol feature is switched off (denoted by woAqual),(b) the quality flag for the cloud feature is switched off (woCqual), and (c) the quality flags for both aerosol and cloud features are switched off (woACqual). Note that the percentage differences are with respect to the case when the strictest quality criteria were used.
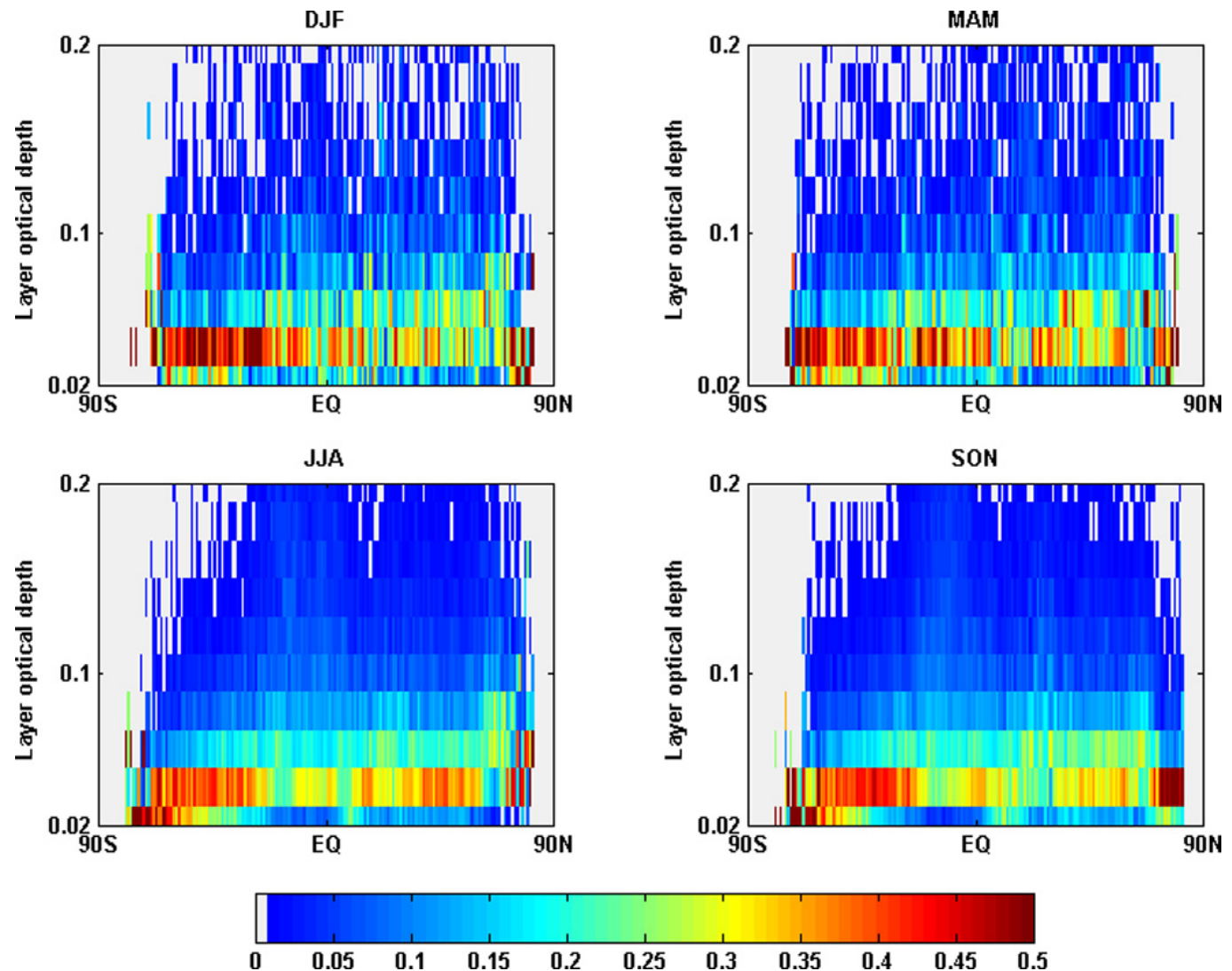

Fig. 6. The zonal seasonal distribution of optical depths of the overlying aerosol layers for the AAO case. Each bin in is 0.02 optical depth units by one degree latitude. Each optical depth bin along y-axis is normalized by the total number of observations at a particular latitude bin. 


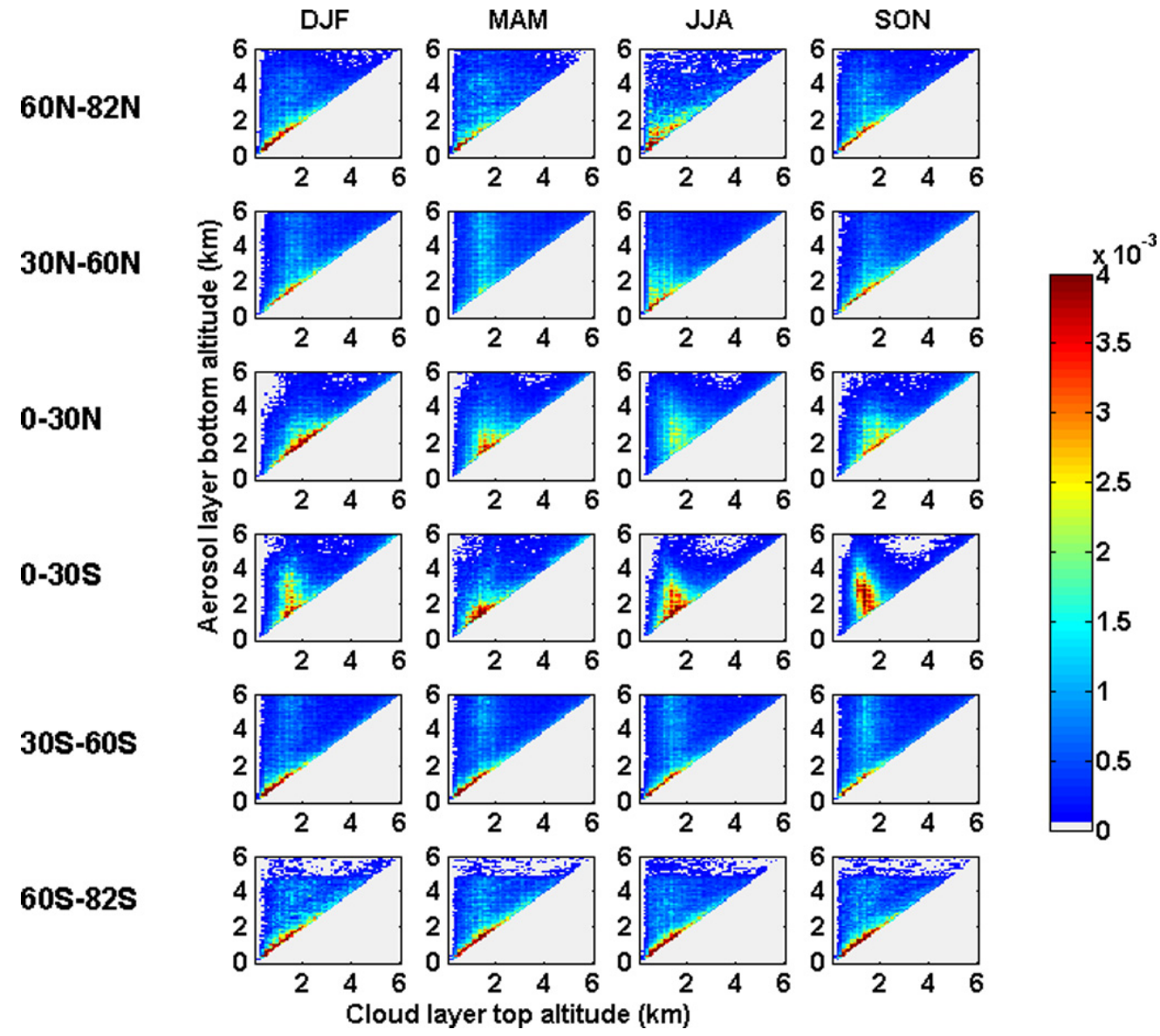

Fig. 7. The joint histograms of cloud layer top altitude and aerosol layer base altitude in overlapping cases when overlap from all aerosol types is considered. The bin size is $100 \mathrm{~m}$ by $100 \mathrm{~m}$ and the observations in each height-height bin are normalized by the total number of observations in the entire histogram.

layer base altitudes, and their geometrical thicknesses are expressed in terms of joint histograms as shown in Figs. 7 and 8 for the AAO case. The histograms are computed for six latitude bands $\left(60^{\circ} \mathrm{N}-90^{\circ} \mathrm{N}, 30^{\circ} \mathrm{N}-60^{\circ} \mathrm{N}, 0-30^{\circ} \mathrm{N}, 0-30^{\circ} \mathrm{S}\right.$, $30^{\circ} \mathrm{S}-60^{\circ} \mathrm{S}$, and $60^{\circ} \mathrm{S}-90^{\circ} \mathrm{S}$ ) and for four seasons. It can be seen from Fig. 7 that, in the bulk of overlapping events, cloud layer top and aerosol layer base altitudes are within the lowermost $3 \mathrm{~km}$ of the troposphere. In the tropical regions, aerosol layer bases are $2-3 \mathrm{~km}$ high in $30-35 \%$ cases, and altogether in more than $50 \%$ cases they are within 2 $4 \mathrm{~km}$ (Fig. 9a). About 45-50\% aerosol layers have their bases within $1-3 \mathrm{~km}$ in the polar regions. In almost all latitudinal bands, the bulk of cloud layers have their tops within $1-2 \mathrm{~km}$ (about $60 \%$ in $0-30^{\circ} \mathrm{S}$ to about $45 \%$ in the polar regions).

There is a clear tendency that the vertical separation between aerosol and cloud layers to increase from high to low latitude regions in both hemispheres. In the polar regions, the maximum in frequency distribution is aligned diagonally in joint histograms suggesting that, in most cases, aerosol and cloud layers are spaced very close to each other, while at lower latitudes, maxima in the distributions have a large scatter diagonally. We attribute this to the spatio-temporal variability of aerosol sources together with the large scale atmospheric circulation patterns are mostly responsible for such a hemispheric tendency in the vertical separation of aerosol and cloud layers. For example, in the tropical bands where a large scatter in joint histograms is observed, dust and biomass burning aerosols are convected/injected to higher altitudes and then transported over nearby regions where low level clouds are present. In the polar regions, large scale subsidence and strong and persistent inversions (Devasthale et al., 2010) lead to very high stability. Fig. 9c shows the cumulative frequency of the vertical distance between aerosol and cloud layers. In general, in about $5-10 \%$ cases the vertical distance between aerosol and cloud layers is less than $100 \mathrm{~m}$, while about in 45-60\% cases it less than a kilometer in the annual means for different latitudinal bands.

Figure 7 also depicts seasonal variability in the aerosol and cloud layer separation for various latitude bands. Intraannual variability also increases from high to low latitudes. The latitude band of $0-30^{\circ} \mathrm{S}$ exhibits the highest seasonal variability mostly driven by seasonalilty in the biomass 


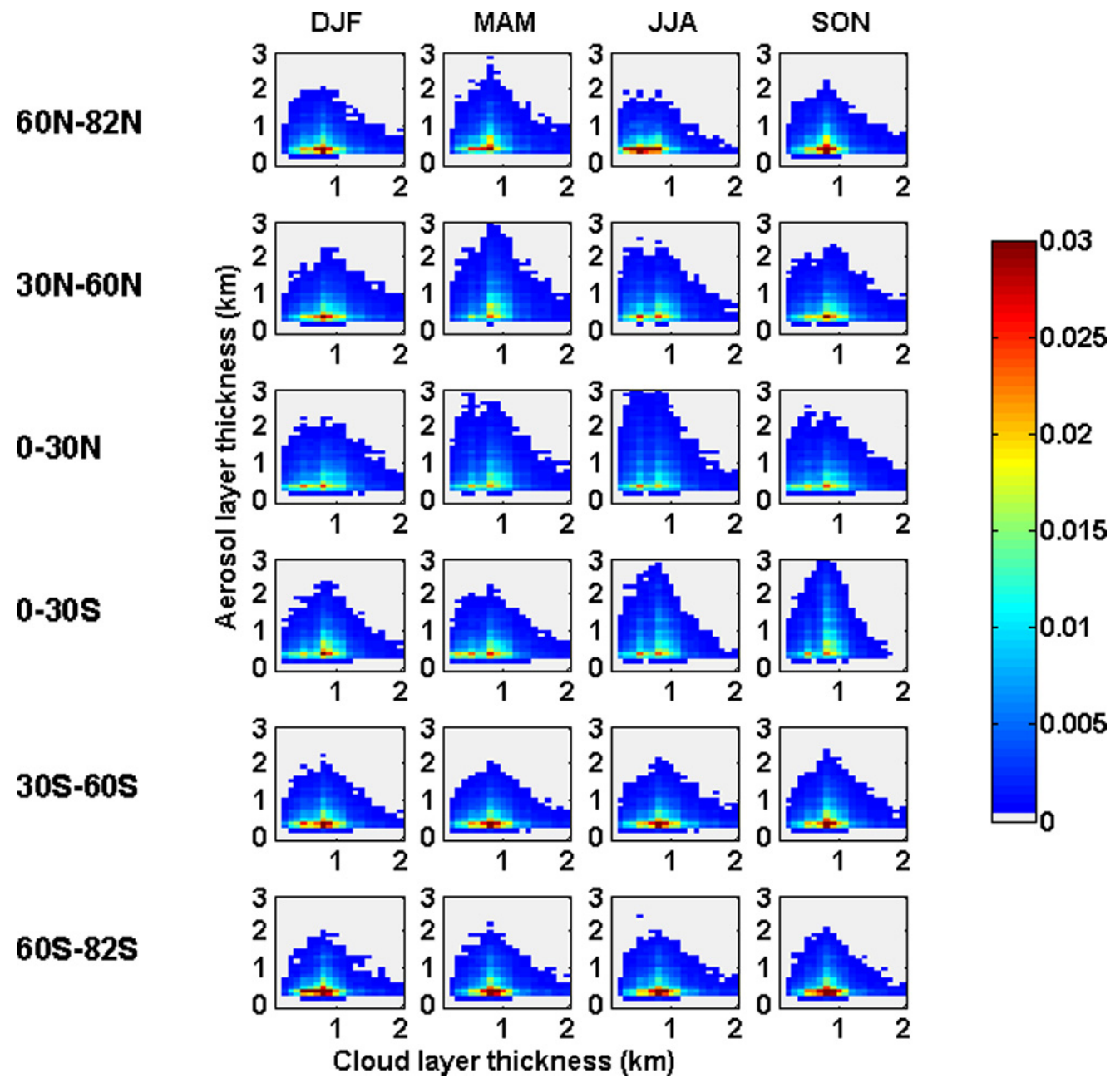

Fig. 8. Joint histograms of cloud and aerosol layer geometrical thicknesses in overlapping cases when overlap from all aerosol types is considered. The binning and normalization is same as in Fig. 7.

burning events over the sub-Saharan and central African regions. Aerosols injected at high altitudes over the biomass burning regions in South America, which are then advected over the eastern Pacific Ocean across the Andes by easterly and southeasterly winds, also contribute to this observed variability. In general, while cloud layer tops are mostly below $2 \mathrm{~km}$, the bulk of aerosol layers can remain as high as $4 \mathrm{~km}$. The $0-30^{\circ} \mathrm{N}$ latitude band also shows high seasonal variability due to seasonality in pure and polluted dust aerosols. The largest vertical separation between aerosol and cloud layers is observed over the $0-30^{\circ} \mathrm{S}$ latitude band and for the SON months.

The majority of aerosol and cloud layers have geometrical thicknesses less than a kilometer during overlap events (Figs. 7 and 9d). In most cases, cloud layers are thicker than aerosol layers over all latitude bands and seasons, but the frequency of occurrence of thicker aerosol layers gradually increases from the poles to the tropics. The distributions of aerosol layer thickness are narrow over the polar regions, while they are much broader over the tropical regions. Aerosol layers can be occasionally as thick as $4 \mathrm{~km}$ over the tropical regions. In about $70-80 \%$ cases, aerosol layers are less than a kilometer thick, while in about $18-22 \%$ cases they are $1-2 \mathrm{~km}$ thick. The frequency of aerosol layers $2-3 \mathrm{~km}$ thick is about $4-5 \%$ in the tropical belts during overlap events.

\section{Conclusions and implications}

We present, for the first time, a global overview of aerosolliquid water cloud overlap using four years of collocated CALIPSO $5 \mathrm{~km}$ Aerosol and Cloud V3 Layer products (June 2006-May 2010). The presence of aerosols over highly reflective surfaces, such as bright water cloud tops, could significantly alter their net radiative effect. A quantitative assessment of aerosol-cloud overlap is necessary to fully understand aerosol direct and indirect effects, and to estimate 
a)

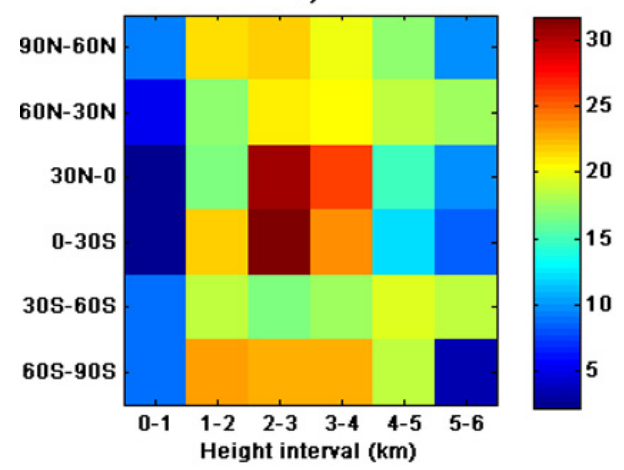

c)

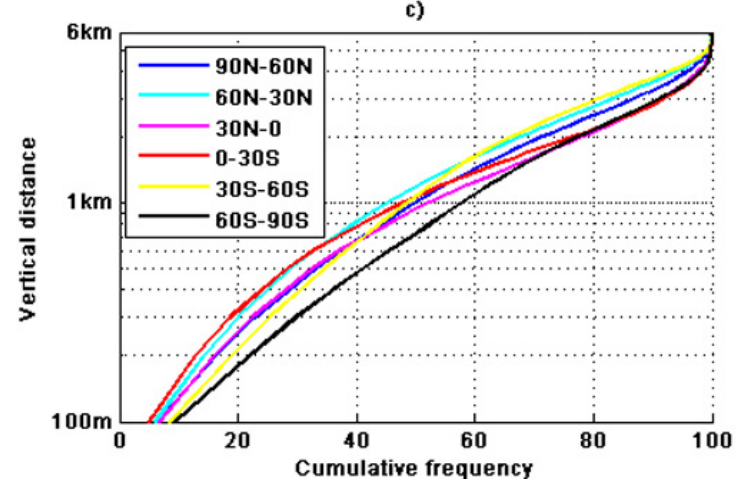

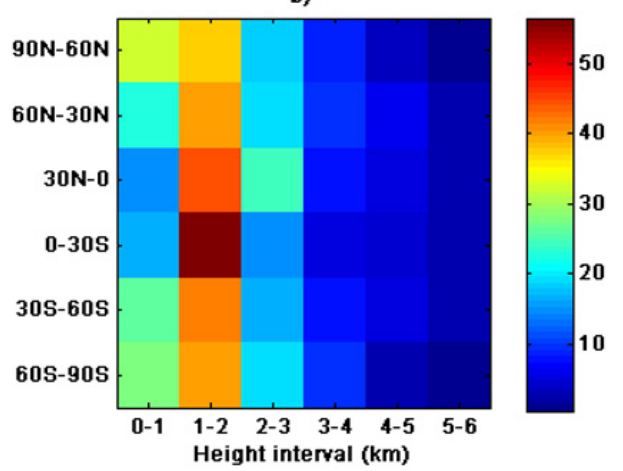

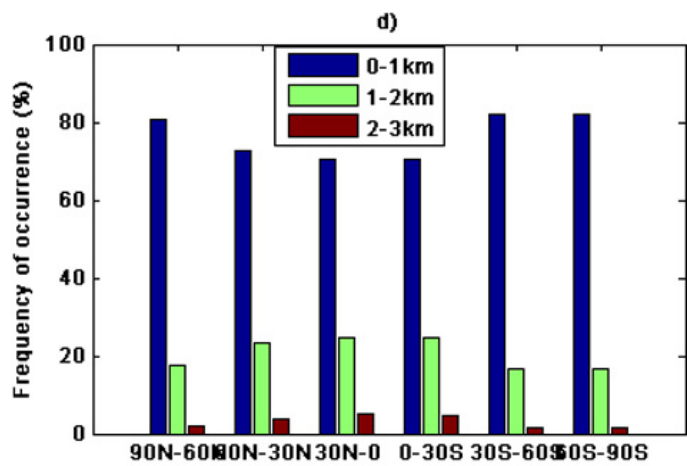

Fig. 9. Annual mean (a) frequency of occurrence of aerosol layer base altitudes; (b) frequency of occurrence of cloud layer top altitudes; (c) cumulative frequency of the vertical distance between aerosol and cloud layers; and (d) frequency of occurrence of aerosol layer geometrical thickness in the intervals of $0-1 \mathrm{~km}, 1-2 \mathrm{~km}$ and $2-3 \mathrm{~km}$. Note that all of these statistics are computed only for cases when overlap was observed.

the uncertainties in cloud property retrievals from passive remote sensing instruments. The capability of CALIPSO to vertically resolve overlapping cases is exploited in the present study to understand the frequency of such overlaps and their global seasonal distribution. The characteristics of overlap events are examined in terms of joint histograms of cloud layer top altitude and aerosol layer base altitude, and cloud and aerosol layer geometrical thicknesses in overlapping events.

The results show a distinct seasonality in overlap frequency in both AAO (all aerosols) and SAO (smoke aerosols) cases. Globally, the frequency is highest during the JJA months in the AAO case, which is most likely due to the dominance of dust and smoke aerosols over low level water clouds. While for the SAO case, it is highest in the SON months due to the dominance of smoke from biomass burning. The seasonal mean overlap frequency can regionally exceed $20 \%$ in the AAO case and $10 \%$ in the SAO case. It is to be noted that these are the lowermost estimates of overlap frequency due to the use of only the highest quality observations. Over the regions where high aerosol loadings are present, the overlap frequency can be up to $50 \%$ higher when quality criteria are relaxed. Over the polar regions, more than $50 \%$ of the overlapping aerosol layers have optical thickness less than 0.02 , but the contribution from the relatively optically thicker aerosol layers increases towards the equatorial regions in both hemispheres. In the tropics and the midlatitudes, roughly $30-50 \%$ aerosol layers have optical thickness in the range of $0.02-0.04$. About $10-20 \%$ of aerosol layers have optical depths greater than 0.1 over these regions.

There is a tendency that the vertical separation between aerosol and cloud layers increases from high to low latitude regions in the both hemispheres. In about 5-10\% cases the vertical distance between aerosol and cloud layers is less than $100 \mathrm{~m}$, while about in 45-60\% cases it less than a kilometer in the annual means for different latitudinal bands. The frequency of occurrence of thicker aerosol layers gradually increases from the poles to the tropics. In about 70-80\% cases, aerosol layers are less than a kilometer thick, while in about $18-22 \%$ cases they are $1-2 \mathrm{~km}$ thick. The frequency of aerosol layers $2-3 \mathrm{~km}$ thick is about $4-5 \%$ in the tropical belts during overlap events.

The results from our study imply that the frequency of occurrence of aerosol-water cloud overlaps is far from negligible. There should be more emphasis on observational and modeling studies in this direction to fully quantify radiative impact of observed overlap globally and regionally. For example, by applying constraints from CALIPSO data, 
the studies like Chand et al. (2009), Peters et al. (2009) and Podgorny and Ramanathan (2001) could be further extended to a global scale. It is also necessary to understand differences in the net radiative impact of overlap events over the polar and tropical regions as they exhibit different meteorological regimes. Here, it is observed that, in bulk of overlap events, aerosol and cloud layers are placed vertically very close. Even after allowing for the misclassification of the precise boundaries between the two, this small vertical separation would mean that there is a high likelihood that aerosolcloud interactions are manifested in overlap events. However, it remains to be evaluated in which dominant form and at what magnitude these manifestations occur globally. It is to be noted that the regions where overlap frequency is high, aerosol optical depths are also often large (e.g. optically thick plumes of dust and smoke). Therefore, critical evaluations of accuracy of cloud property retrievals from the heritage sensors (ATSR, AVHRR, and MODIS) are needed over overlap regions if these retrievals are to be used for climate applications.

We have shown that the CALIPSO-CALIOP data are extremely useful in characterizing these otherwise highly complex overlap situations, and these data should provide rigorous constraints on modeling the net radiative impact of aerosol-liquid water cloud overlaps globally. The present study focuses on characterizing macrophyiscal properties of overlapping events, thus only partially exploiting the full capability of CALIPSO-CALIOP observations.

\section{Supplementary material related to this article is available online at: http://www.atmos-chem-phys.net/11/1143/2011/ acp-11-1143-2011-supplement.pdf.}

Acknowledgements. Authors are grateful to the CALIPSO Science Team for their efforts in making data products publicly available. These data were obtained from the NASA Langley Research Center Atmospheric Science Data Center. Authors are also thankful to ISCCP, NASA's GIOVANNI and MODIS Rapid Response System projects for making cloud, aerosol and fire map datasets available for research. Wind data were obtained from the ECMWF's ERA-Interim project. This work was supported by the Swedish National Space Board.

Edited by: K. Carslaw

\section{References}

Andreae, M. O., Artaxo, P., Fischer, H., Freitas, S. R., Grégoire, J.-M., Hansel, A., Hoor, P., Kormann, R., Krejci, R., Lange, L., Lelieveld, J., Lindinger, W., Longo, K., Peters, W., de Reus, M., Scheeren, B., Silva Dias, M. A. F., Ström, J., van Velthoven, P. F. J., and Williams, J.: Transport of biomass burning smoke to the upper troposphere by deep convection in the equatorial region, Geophys. Res. Lett., 28(6), 951954, doi:10.1029/2000GL012391, 2001.

Brioude, J., Cooper, O. R., Feingold, G., Trainer, M., Freitas, S. R., Kowal, D., Ayers, J. K., Prins, E., Minnis, P., McKeen, S. A., Frost, G. J., and Hsie, E.-Y.: Effect of biomass burning on marine stratocumulus clouds off the California coast, Atmos. Chem. Phys., 9, 8841-8856, doi:10.5194/acp-9-8841-2009, 2009.

Carslaw, K. S., Boucher, O., Spracklen, D. V., Mann, G. W., Rae, J. G. L., Woodward, S., and Kulmala, M.: A review of natural aerosol interactions and feedbacks within the Earth system, Atmos. Chem. Phys., 10, 1701-1737, doi:10.5194/acp-10-17012010, 2010.

Chand, D., Anderson, T. L., Wood, R., Charlson, R. J., Hu, Y., Liu, Z., and Vaughan, M.: Quantifying above-cloud aerosol using spaceborne lidar for improved understanding of cloudysky direct climate forcing, J. Geophys. Res., 113, D13206, doi:10.1029/2007JD009433, 2008.

Chand, D., Wood, R., Anderson, T. L., Satheesh S. K., and Charlson, R. J.: Satellite-derived direct radiative effect of aerosols dependent on cloud cover, Nat. Geosci., 2, 181-184, doi:10.1038/NGEO437, 2009.

Devasthale, A., Willn, U., Karlsson, K.-G., and Jones, C. G.: Quantifying the clear-sky temperature inversion frequency and strength over the Arctic Ocean during summer and winter seasons from AIRS profiles, Atmos. Chem. Phys., 10, 5565-5572, doi:10.5194/acp-10-5565-2010, 2010.

reitas, S. R., Longo, K. M., Silvia Dias, M. A. F., Silva Dias, P. L., Chatfield, R., Prins, E., Artaxo, P., Grell G. A., and Recuero, F. S.: Monitoring the transport of biomass burning emissions in South America, Environ. Fluid Dyn., 5, 135-167, 2005.

Hu, Y., Winker, D., Vaughan, M., Lin, B., Omar, A., Trepte, C., Flittner, D., Yang, P., Nasiri, S. L., Baum, B., Sun, W., Liu, Z., Wang, Z., Young, S., Stamnes, K., Huang, J., Kuehn, R., and Holz, R.: CALIPSO/CALIOP cloud phase discrimination algorithm, J. Atmos. Ocean. Tech., 26, 2293-2309, 2009.

Intergovernmental Panel of Climate Change (IPCC), The Physical Science Basis, Contribution of Working Group I to the Fourth Assessment Report of the IPCC 916, Cambridge Univ. Press, 2007.

Koren, I., Remer, L. A., Kaufman, Y. J., Rudich, Y., and Martins, J. V.: On the twilight zone between clouds and aerosols, Geophys. Res. Lett., 34, L08805, doi:10.1029/2007GL029253, 2007.

Koren, I., Oreopoulos, L., Feingold, G., Remer, L. A., and Altaratz, O.: How small is a small cloud?, Atmos. Chem. Phys., 8, 38553864, doi:10.5194/acp-8-3855-2008, 2008.

Liu, Z., Vaughan, M. A., Winker, D. M., Kittaka, C., Kuehn, R. E., Getzewich, B. J., Trepte, C. R., and Hostetler, C. A.: The CALIPSO Lidar Cloud and Aerosol Discrimination: Version 2 Algorithm and Initial Assessment of Performance, J. Atmos. Oceanic Technol., 26, 1198-1213, doi:10.1175/2009JTECHA1229.1, 2009.

Lohmann, U. and Feichter, J.: Global indirect aerosol effects: a review, Atmos. Chem. Phys., 5, 715-737, doi:10.5194/acp-5-7152005, 2005.

Omar, A., Winker, D., Kittaka, C., Vaughan, M., Liu, Z., Hu, Y., Trepte, C., Rogers, R., Ferrare, R., Kuehn, R., Hostetler, C.: The CALIPSO Automated Aerosol Classification and Lidar Ratio Selection Algorithm, J. Atmos. Oceanic Technol., 26, 1994-2014, doi:10.1175/2009JTECHA1231.1, 2009. 
Peters, K., Quaas, J., and Bellouin, N.: Effects of absorbing aerosols in cloudy skies: a satellite study over the Atlantic Ocean, Atmos. Chem. Phys. Discuss., 9, 20853-20880, doi:10.5194/acpd9-20853-2009, 2009.

Podgorny, I. A. and Ramanathan, V.: A modeling study of the direct effect of aerosols over the tropical Indian Ocean, J. Geophys. Res., 106, 24097-24105, 2001.

Quaas, J., Ming, Y., Menon, S., Takemura, T., Wang, M., Penner, J. E., Gettelman, A., Lohmann, U., Bellouin, N., Boucher, O., Sayer, A. M., Thomas, G. E., McComiskey, A., Feingold, G., Hoose, C., Kristjánsson, J. E., Liu, X., Balkanski, Y., Donner, L. J., Ginoux, P. A., Stier, P., Grandey, B., Feichter, J., Sednev, I., Bauer, S. E., Koch, D., Grainger, R. G., Kirkevåg, A., Iversen, T., Seland, Ø., Easter, R., Ghan, S. J., Rasch, P. J., Morrison, H., Lamarque, J.-F., Iacono, M. J., Kinne, S., and Schulz, M.: Aerosol indirect effects - general circulation model intercomparison and evaluation with satellite data, Atmos. Chem. Phys., 9, 8697-8717, doi:10.5194/acp-9-8697-2009, 2009a.

Quaas, J., Stevens, B., Stier, P., and Lohmann, U.: Interpreting the cloud cover - aerosol optical depth relationship found in satellite data using a general circulation model, Atmos. Chem. Phys., 10, 6129-6135, doi:10.5194/acp-10-6129-2010, 2010b.

Remer, L. A., Kleidman, R. G., Levy, R. C., Kaufman, Y. J., Tanré , D., Mattoo, S., Vanderlei Martins, J., Ichoku, C., Koren, I., Yu, H., and Holben, B. N.: Global aerosol climatology from the MODIS satellite sensors, J. Geophys. Res., 113, D14S07, doi:10.1029/2007JD009661, 2008.

Satheesh, S. K., Krishna Moorthy, K., Kaufman, Y. J., and Takemura, T.: Aerosol optical depth, physical properties and radiative forcing over the Arabian Sea, Meteorol. Atmos. Phys., 91, 45-62, 2006.
Stevens, B. and Feingold, G.: Untangling aerosol effects on clouds and precipitation in a buffered system, Nature, 461, 607-613, 2009.

Vaughan, M., Powell, K., Kuehn, R., Young, S., Winker, D., Hostetler, C., Hunt, W., Liu, Z., McGill, M., and Getzewich, B.: Fully Automated Detection of Cloud and Aerosol Layers in the CALIPSO Lidar Measurements, J. Atmos. Oceanic Technol., 26, 2034-2050, doi:10.1175/2009JTECHA1228.1, 2009.

Waquet, F., J. Riedi, L. C. Labonnote, AND P. Goloub, B. Cairns, J.-L. Deuze, and D. Tanre, Aerosol Remote Sensing over Clouds Using A-Train Observations, J. Atmos. Sci., 66, 2468-2480, 2009.

Wilcox, E. Harshvardhan, M., and Platnick, S.: Estimate of the impact of absorbing aerosol over cloud on the MODIS retrievals of cloud optical thickness and effective radius using two independent retrievals of liquid water path, J. Geophys. Res., 114, D05210, doi:10.1029/2008JD010589, 2009.

Winker, D. M., Vaughan, M. A., Omar, A. H., Hu, Y., Powell, K. A., Liu, Z., Hunt, W. H., and Young, S. A.: Overview of the CALIPSO Mission and CALIOP Data Processing Algorithms, J. Atmos. Oceanic Technol., 26, 2310-2323, doi:10.1175/2009JTECHA1281.1, 2009.

Young, S. A. and Vaughan, M. A.: The retrieval of profiles of particulate extinction from Cloud Aerosol Lidar Infrared Pathfinder Satellite Observations (CALIPSO) data: Algorithm description, J. Atmos. Oceanic Technol., 26, 1105-1119, doi:10.1175/2008JTECHA1221.1, 2009. 